\title{
Further studies on phenol removal from aqueous solutions by solvent extraction
}

\author{
R. M.Abdelmonem, M. A. Hashem and A. A. Mohmed \\ Chem. Eng Dept., Faculty of Engineering, El-Minia University, \\ El-Minia, Egypt
}

\begin{abstract}
The removal of phenol from aqueous solutions by solvent extraction has been investigated. Batch experiments were conducted to determine the effect of different solvents (four solvents) on the rate of phenol removal from dilute aqueous solution. The effect of $\mathrm{pH}$, contact time, solvent/feed ratio, shaking time and agitation speed on the removal of phenol by each solvent were investigated. The equilibrium condition was also determined and the rate of extraction was measured as a function of the above. The performance of each solvent is discussed with respect to the operating conditions. The results lead strongly towards the use of methyl iso-butyl keton (MIBK) and di-isopropyl ether (DIPE) as a preferred solvent. Based on the results of the experiments the operating conditions were proposed and $95-98 \%$ phenol was removed depending on the type of solvent used.
\end{abstract}

\section{Introduction}

Nature contains many fortunes like coal and petroleum. These natural fortunes usually can not be used in their original form, so they undergo certain treatments to improve their properties, for example, petroleum refinery, coke oven plants and phenol resin plants. These processes are the main cause of the wastewater contamination with phenol, where the concentration of phenol ranges from 1000 $\mathrm{ppm}$ to $6000 \mathrm{ppm}$. Phenols are readily biodegraded unless they are at high concentration, which are toxic to the microorganism and cause flesh of fish. Aqueous phenol solutions make an interesting case study for liquid extraction because they represent a common waste disposal problem.

However, there are many methods have been studied for extraction of phenol from aqueous solutions. Among them is the extraction of phenol using sulfuric acid salts of trioctylamine in a supported liquid membrane [1]. Phenol can be removed from wastewater by the electrochemical technique, which was studied 
at platinum and DSA anode [2]. Also phenol can be removed by adsorption on anion exchange resins [3]. The oxidation technique was studied by Al-Enezi, et,al. [4]. Now the activation carbon is widely used as an effective adsorbent of phenol $[5,6,7]$. The use of activated carbon as an adsorbent is much expensive, so the trend now is using other inexpensive adsorbents instead of activated carbon.

Among recovery process solvent, extraction is generally preferable over steam stripping for phenol removal, since the phenol water system form an isotropic at 9.2 wt. \% phenol. Benzene, butyl acetate have been used as solvents for extraction in the past, but the most common solvent at present is di-isopropyl ether (DIPE), which is used in the phenosolvan process [8]. Another recent process appears to use methyl iso- butyl keton (MIBK) as a solvent $[9,10,11]$.

The aim of the present work is to study the effect of different solvents, namely; DIPE, toluene, benzene and MIBK on the rate of phenol removal from dilute aqueous solution by conducting a series of batch extraction tests using shaker apparatus to optimize the design parameters for the full-scale extraction process. The effect of $\mathrm{pH}$, contact time, solvent/feed ratio, agitation time and speed on the removal of phenol by each solvent were investigated. The equilibrium condition was also determined and the rate of extraction was measured as a function of the above. The performance of each solvent is discussed with respect to the operating conditions.

\section{Experimental part}

The desired quantity of pure solvent is added to the aqueous phenol solution in a $250-\mathrm{ml}$ glass bottle. Then the bottle is put in a shaker, which can be adjusted at the desired values of agitation (stroke/min), temperature and time.

After the desired time is elapsed, the bottle is taken off from the shaker and the solvent is separated from the aqueous raffinite using separatory funnel, in which the sample is rested for $30 \mathrm{~min}$, so that the separation of the two phases is completely achieved. The concentration of the lower layer is determined by using spectrophotometer (UV-1601 Shimadzu).

\section{Results and discussion}

\subsection{Effect of solvent to feed ratio}

Generally, increasing the amount of solvent will increase the removal of the solute from its mother liquor. Figures $(1,2,3$, and 4) show the concentrations of the final aqueous solutions against time for the various solvents at different values of solvent to feed ratio (S/F). Figures $(1 \& 3)$, when using DIPE and benzene, indicate that: the changing of $S / F$ ratio from $1: 1$ to $2: 1$ has a large effect more that obtained by changing the ratio from $2: 1$ to $3: 1$. Also, indicate that, $S / F$ ratio have no affect on the equilibrium time, especially at the higher values of $\mathrm{S} / \mathrm{F}$.

Figures $(2, \& 4)$, when using toluene and MIBK, indicate that: increasing the S/F ratio will improve the extraction process. It is clear that the optimum residence time for each solvent used is within $15 \mathrm{~min}$, after that time, the rate of decreasing phenol concentration in the final solution is almost constant. 

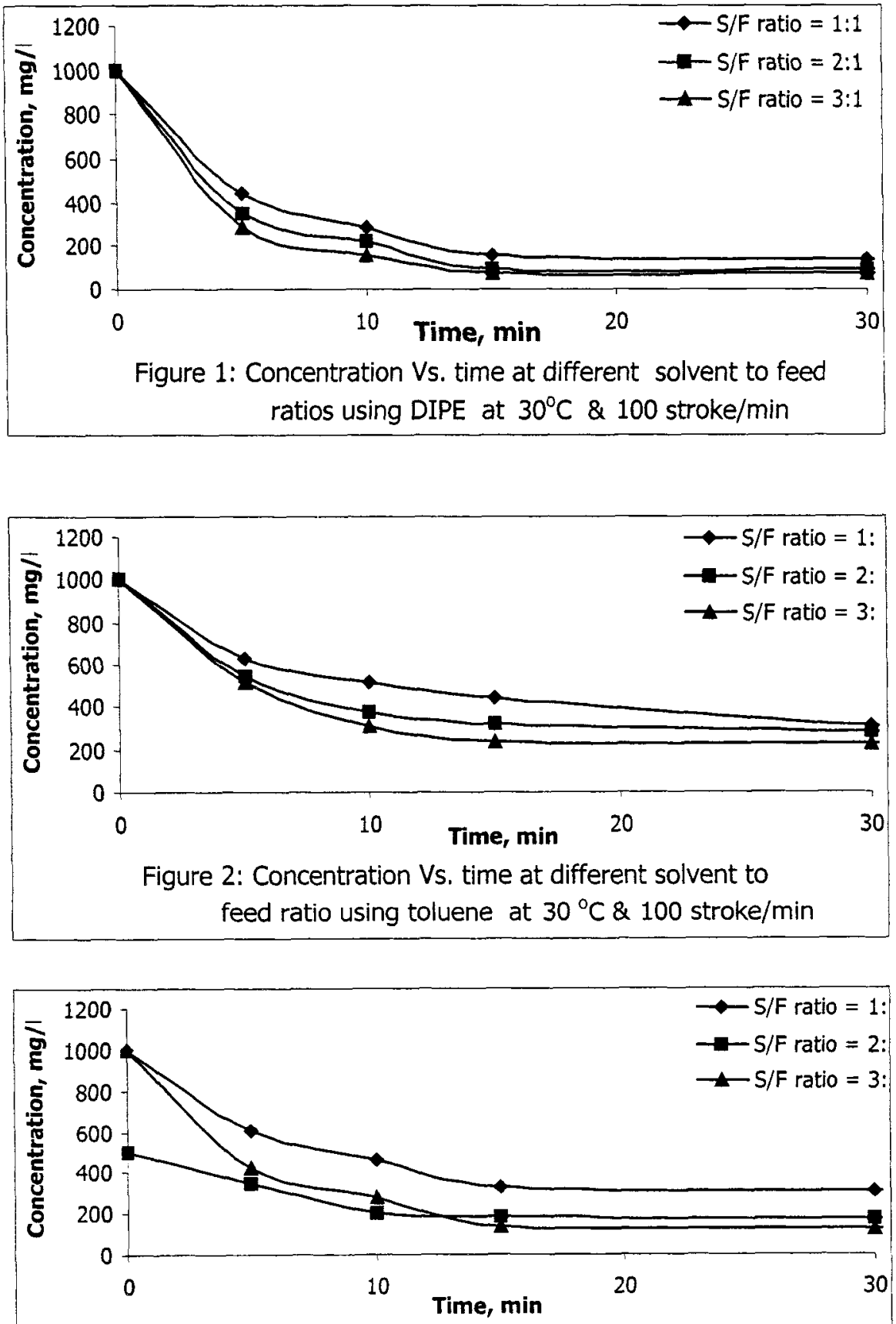

Figure 3: Concentration Vs. time at different solvent to feed ratio using benzene at $30^{\circ} \mathrm{C} \& 100$ stroke/min 


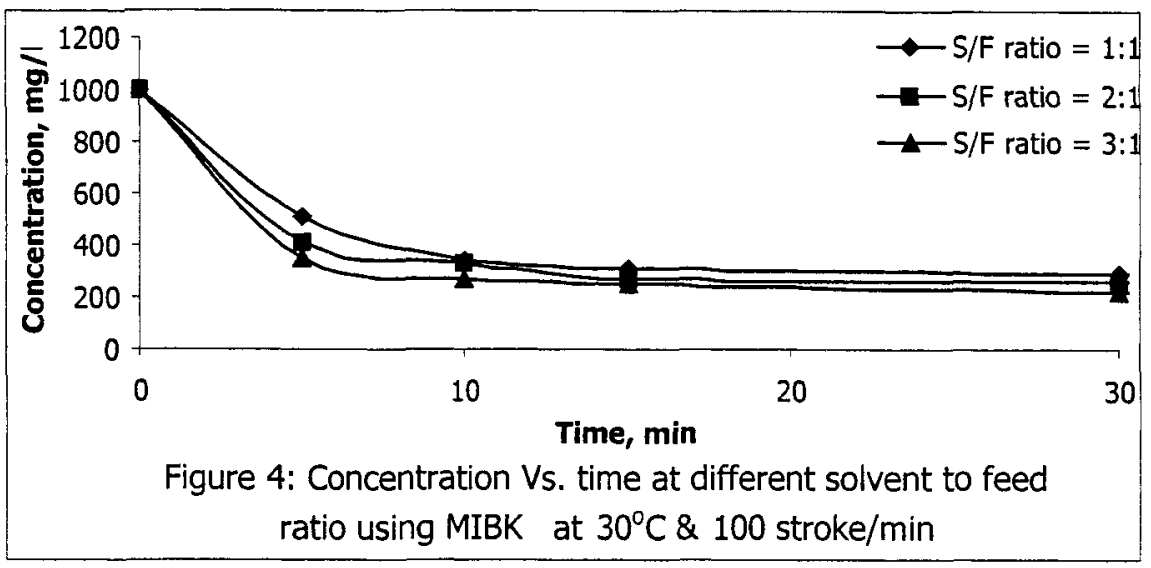

\subsection{Effect of agitation speeds}

Figures $(5,6,7, \& 8)$ show the effect of the agitation speed using the different four solvents. These figures indicate that, the extraction rate increases with increasing the agitation speed for all solvents. The extraction process is considered as diffusion controlled in which the contact area increases and hence the rate of mass transfer increases due to the impregnation of one liquid through the other.

Moreover, the figures indicate that, the optimum residence time depends on the solvent used and sometimes on the value of the speed. For example, by using toluene, Figure (6) shows the optimum residence time is about $30 \mathrm{~min}$, after that the decreasing rate of the phenol concentration is nearly constant. While, for the other solvents, the residence time is $15 \mathrm{~min}$. This may be attribute to the low affinity of toluene to extract phenol by varying speed of the process, while the other solvents have high affinity.

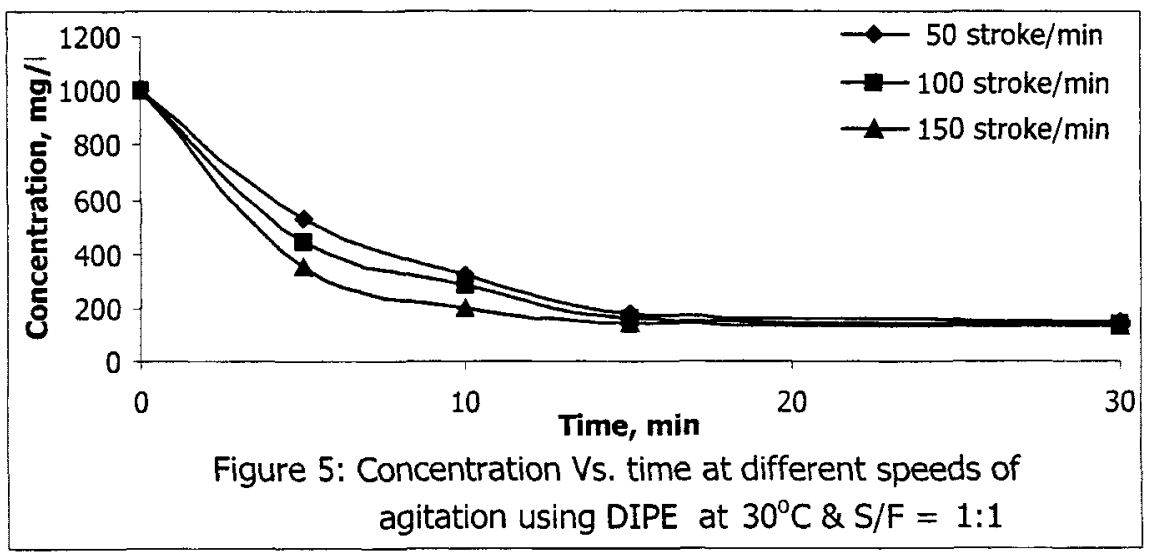



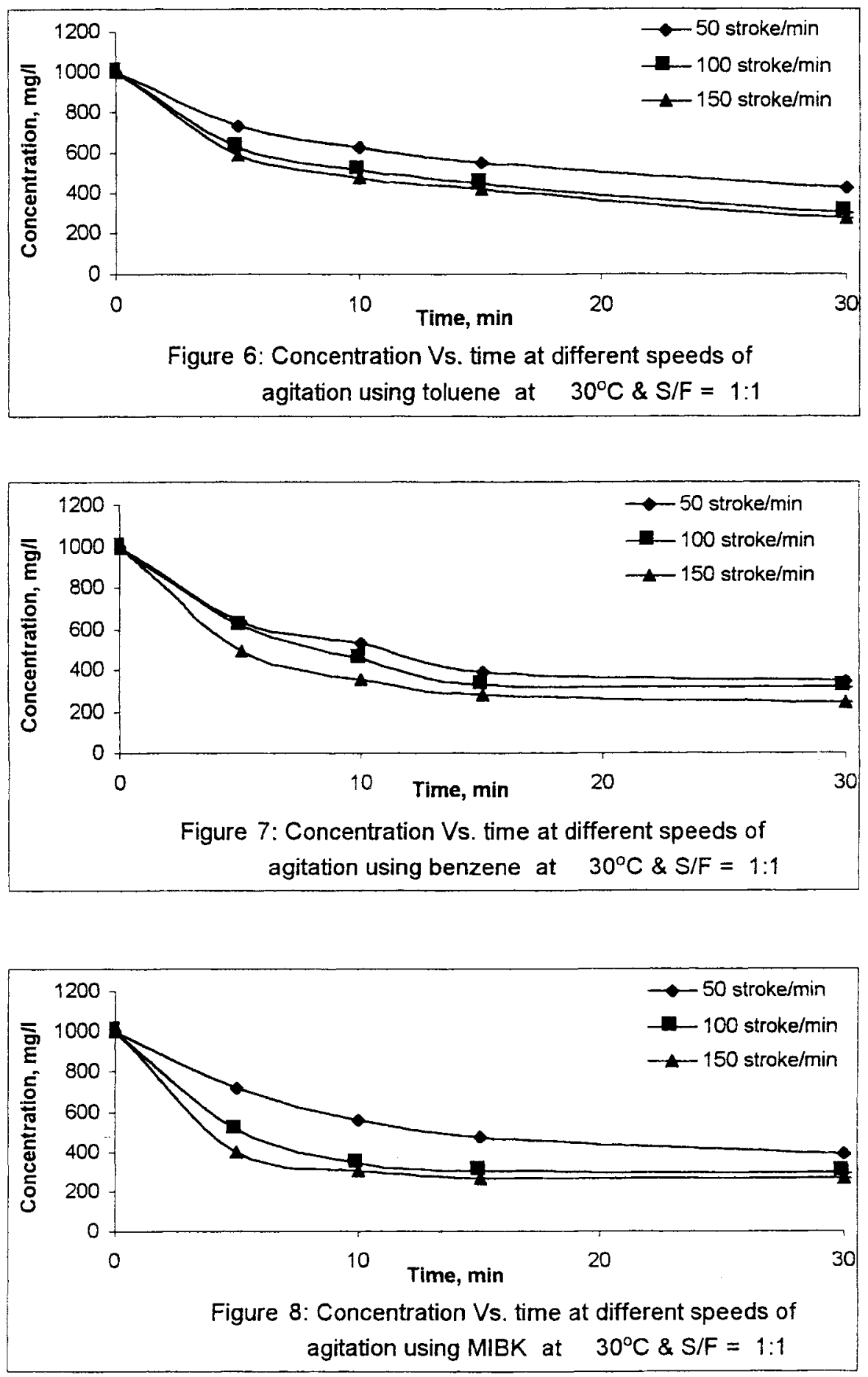


\section{Environmental Health Risk}

\subsection{Effect of Temperatures}

Figures $(9, \& 10)$ show the effects of the temperatures on the rate of phenol removal, by examining these figures, it is noted that, the rate of extraction increases by increasing the temperature. The figures also indicate that, the rate of reaction is slightly increasing with the increasing of the temperatures, which means that the extraction process is physically not chemically in nature.
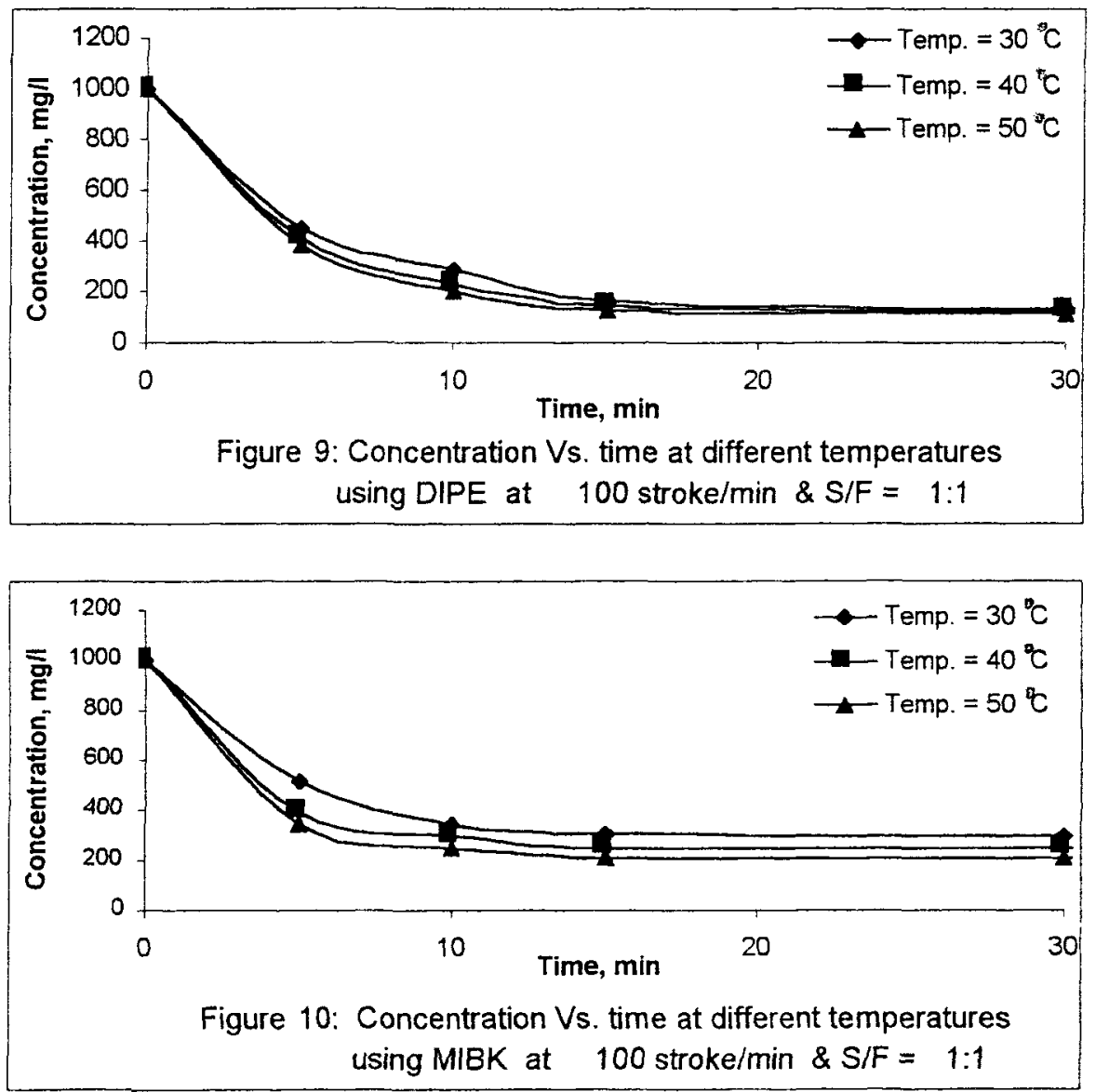
The values of distribution coefficient found at $30{ }^{\circ} \mathrm{C}, 40{ }^{\circ} \mathrm{C}$, and $50{ }^{\circ} \mathrm{C}$ are shown in figure (11) as a function of weight fraction of phenol in the organic phase. The values of $\mathrm{K}_{d}$ (equilibrium distribution coefficient) are uniformly high but are highest at low temperature, indicating that the extraction at low temperature is desirable. The values of $\mathrm{K}_{d}$ at higher phenol concentration were not investigated since it is unlikely that such concentration level would be achieved in the solvent, even for waste stream relatively rich in phenol. Data were also taken at the same temperature to determine the mutual solubility of MIBK, toluene, benzene and water. The results are in a good agreement with the results of Gross et al.[12]. The values which is the most important to the process are the solubility's of the solvent in water, which should be as low as possible in order to keep energy loads associated with solvent recovery low. These data would be appears to indicate that higher extraction temperatures are desirable.

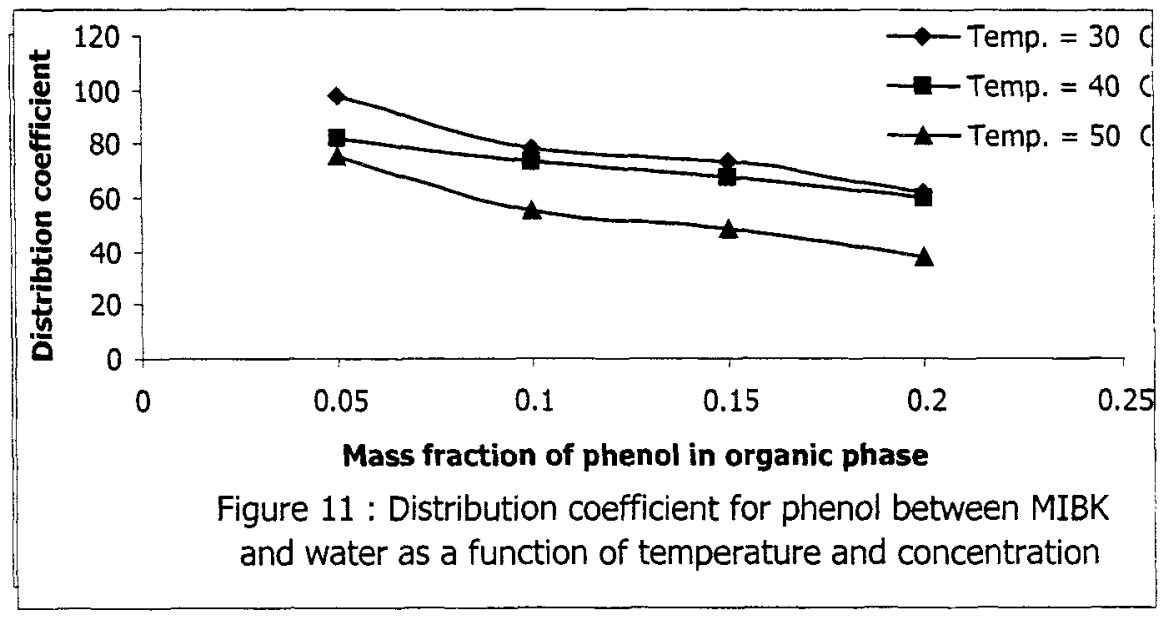

\subsection{Effect of $\mathrm{pH}$}

Figure (12) show the effects of the $\mathrm{pH}$ on the phenol extraction process, this figure indicates that, the best extraction takes place in the $\mathrm{pH}$ range of (4-6), while at the alkaline range, the ability of the extraction is low. This due to that, phenol is a weak acid and dissociates into phonate ion and a proton as shown in the equation.

$$
\mathrm{C}_{6} \mathrm{H}_{5}+\mathrm{H}_{2} \mathrm{O} \Phi \mathrm{C}_{6} \mathrm{H}_{5} \mathrm{O}^{-}+\mathrm{H}_{3} \mathrm{O}^{+}
$$

Phenol ionizes appreciably in aqueous solution when the $\mathrm{pH}$ rivals. Table (1) show the experimentally measured distribution coefficient as a function of water phase $\mathrm{pH}$, phenol distributes between DIPE and water. 


\section{Environmental Health Risk}

Table (1) Distribution coefficient for phenol between DIPE and water as a function of $\mathrm{pH}$ at $25^{\circ} \mathrm{C}$

\begin{tabular}{|c|c|}
\hline Water phase $\mathrm{pH}$ & Distribution coefficient, $\mathrm{K}_{\mathrm{d}}$ \\
\hline 5 & 38 \\
\hline 6 & 38 \\
\hline 7 & 38 \\
\hline 8 & 37 \\
\hline 9 & 36 \\
\hline 10 & 20 \\
\hline 11 & 8 \\
\hline
\end{tabular}

The distribution coefficients data are calculated from the model given by Treybal [13] for a week acid distribute between organic and aqueous phases with dissociation occurring with aqueous phase

$$
K_{d}=\frac{K_{d} \text { low } p H}{K_{a} /\left[H^{+}\right]+1}
$$

Where; $K_{D}$ is the equilibrium distribution coefficient, $K_{a}$ is the acidic dissociation constant, and $\left[\mathrm{H}^{+}\right]$is molar hydrogen ion concentration. By using the values of $\mathrm{K}_{\mathrm{d}}$ measured at low $\mathrm{pH}$ as a single adjustable parameter along with the value of $K_{a}$, there is a good agreement in the results. Since $K_{a}$ is known independently, the model has only one fitted parameter. Similarly, MIBK, DIPE, toluene, and benzene found good agreement with such a model for the extraction of phenol respectively

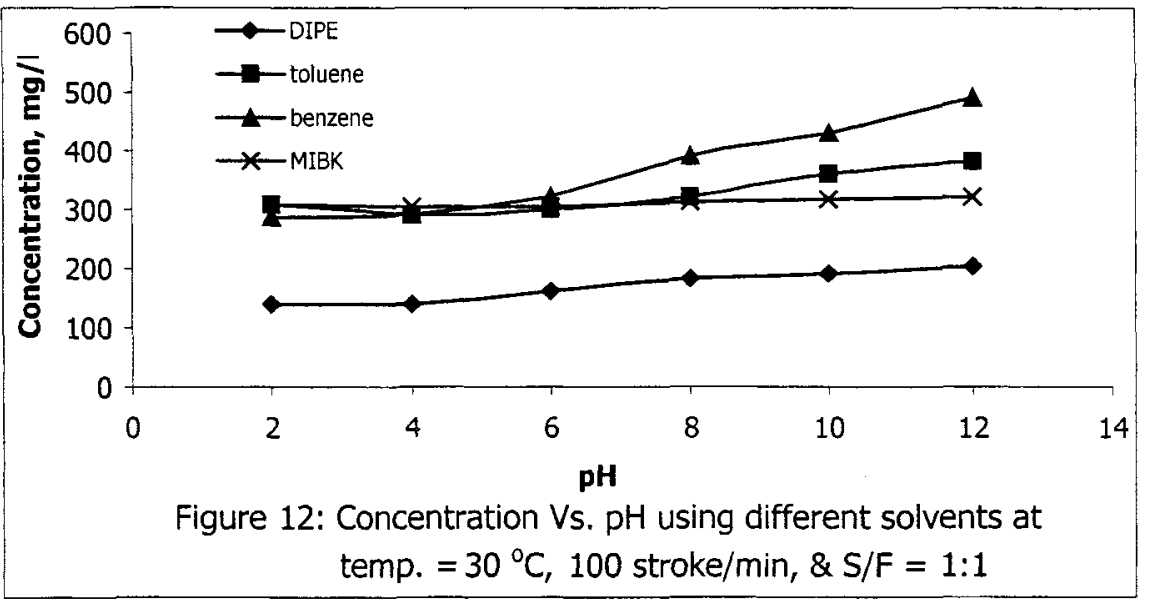

\subsection{Type of solvents}

The most important factors in generation of a process for extraction of polar organic from a dilute water stream is solvent selection. Since water flows are often large, it is important to choose a solvent, which will give a high 
distribution ratio for the solute in questions; this needs to keep solvent circulation rates flow becoming excessive. An effective solvent for highly polar organic frequently has a substantial solubility in water itself. In such case the dissolved solvent must be removed somehow from the raffinate water and the solvent properties must be well suited to whatever process is used for that purpose. For the lowest concentration of soluble organic in the feed water, it will be necessary to regenerate and reuse the solvent, often by distillation or stripping and chemical stability of the solvent under regeneration conditions thereby become important attributes to keep solvent consumption economically low.

There is a general rule states that "Like dissolve like", which, should be taken into consideration in the choice decision of the solvent for the extraction process. This means that the solute and the solvent should have equal polarity, hence they should have a near value of the dielectric constant.

In this study, the solvents used are DIPE, toluene, benzene, and MIBK. Figure (13), shows the concentrations of the final aqueous solutions against time for the different solvents used at the same conditions of temperature $\left(30^{\circ} \mathrm{C}\right), \mathrm{S} / \mathrm{F}$ ratio (1:1), and 100 stroke/min. This figure indicates that; DIPE is the most suitable solvent, MIBK comes next, while all others are equally in their effect. Also, this figure indicates that the equilibrium time for all the solvents is about $15 \mathrm{~min}$. After this time, the changes of the concentrations of aqueous are so small.

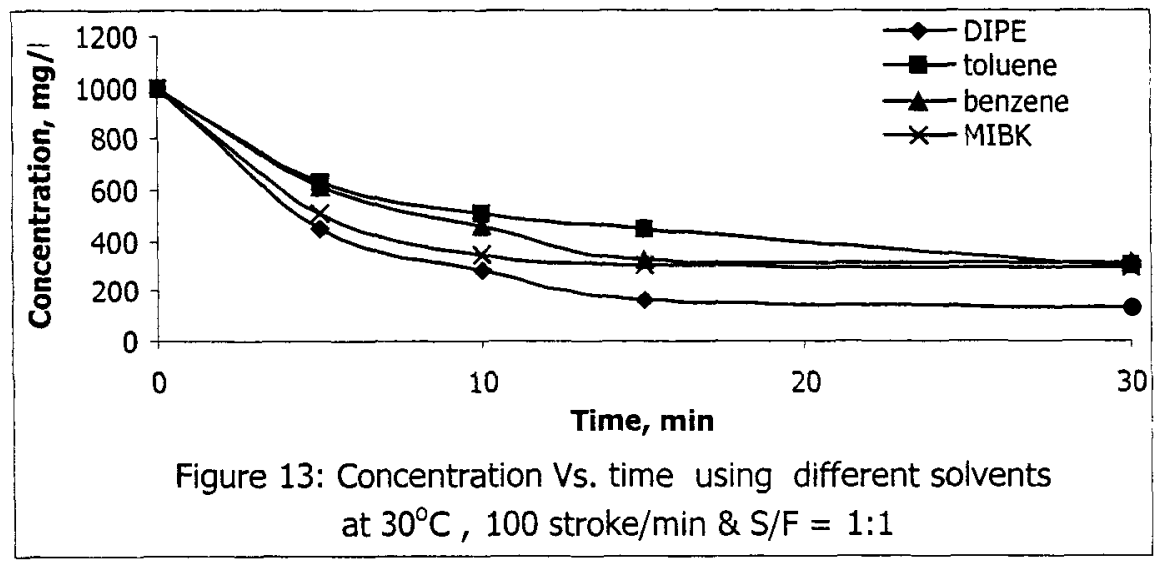

\subsection{Determination of the activation energy}

The activation energy is determined using Arhenius equation:

$$
K=A e^{-E / R T}
$$

By plotting the natural logarithm of the slopes of the first parts for the relationship of temperatures against concentrations as showing in figures (9-10) against $1 / T_{\text {absolute. }}$. The slope is equal to $-E / R$, where $R$ is the gas constant. Table (2) contains the values of activation energy for the solvents used. 
Table 2. The activation energy for the solvents used

\begin{tabular}{|c|c|}
\hline Solvent & Activation energy, E, KJ/gmol \\
\hline DIPE & 4.216 \\
\hline toluene & 6.89 \\
\hline benzene & 6.16 \\
\hline MIBK & 5.716 \\
\hline
\end{tabular}

From table (2) it is clear that the activation energy ranges between 4 and 6 $\mathrm{KJ} / \mathrm{mol}$, which indicate that: the process is considered as physically reaction and controlled by diffusion.

\section{Conclusion}

In this work the feasibility for the use of simple shaker apparatus for phenol removal from aqueous solutions using different solvents were investigated. Many solvents have been used for extraction of phenol from water. The preferred solvent is whose solubility in water can be tolerated eliminating the need for further purification steps. From the results it can be concluded that DIPE give much higher value of phenol removal than other solvent. The selectivity of a solvent for a given solute depends primarily upon the nature of the solvent, the temperature of the system, and the concentration of the component involved. The maximum percent removal of phenol is $98 \%$ using DIPE at solvent to feed ratio $3: 1$, temperature $30^{\circ} \mathrm{C}$ and 100 stroke/min., while $97 \%$ is achieved by using MIBK at the same operating conditions.

\section{References}

[1] M.L Wang and K. Hua Hu. Extraction of phenol using sulfuric acid salts of trioctylamine in a supported liquid membrane. Ind. Eng. Chem. Res., 33, 914,1994

[2] C. Comninellis. Electrochemical treatment of waste water containing phenol. ICHEME Symposium Series No. 127, 189, 1992

[3] T. C. Huang and L.T. Cho. The adsorption of phenol on anion exchange resins in the presence of p-nitrophenol. Chem. Eng. Comm. 74, 169, 1988

[4] G. Al-Enezi, H.Shaban and M.S.E. Abdo. Total organic carbon reduction of phenol containing wastewater by oxidation. Desalination, 95, 1, 1994

[5] A. Saler and J.L. Slabbert. A preliminary comparison between various granular activated carbon for water reclamation. Water S. A. vol.6, No. 4, October, 1980

[6] R. Johansson. Adsorption on activated carbon in counter flow. Chem. Eng. Sci., 35, 979, 1980

[7] G. McKay. Fluidized bed adsorption of pollutants on activated carbon. Chem. Eng. J., 39, 87, 1988

[8] Beychok, M.R., Coal gasification and the phenosolvan process, American chemical society, Atlantic city NJ, Sep 1974

[9] Scheibel, E.G; Liquid liquid extraction in A Weissberger and E. S. Perge eds, Techniques of chemistry, vol. 12 (separation and purification) $3^{\text {rd }}$ ed., p181, Johnwiley and sons, NewYork, 1978. 
[10] King, J.C, Removal and recovery of carboxylic acids and phenols from dilute aqueous streams, proceeding of ISEC 80, Liege, Belgium, 6-12 Sep., 1980.

[11] King, J. C., Separation process, $2^{\text {nd }}$ ed., p. 367 , McGrawhill book co. inc., Newyork, 1980.

[12] Gross, P.M., Rintelen, J.C. and Saylor, J.H., J. Phys. Chem, 43.197,1969

[13] Treybal, R.E. ; Liquid extraction, $2^{\text {nd }}$ ed., McGraw-Hill, NewYork, 1963 